\title{
The Caveolin-1 Connection to Cell Death and Survival
}

\author{
A.F.G. Quest ${ }^{*}, 1$, L. Lobos-González ${ }^{1}$, S. Nuñez ${ }^{1,4}$, C. Sanhueza ${ }^{1}$, J.-G. Fernández ${ }^{1,2}$, \\ A. Aguirre ${ }^{1}$, D. Rodríguez ${ }^{1}$, L. Leyton ${ }^{1}$ and V. Torres ${ }^{3}$ \\ ${ }^{1}$ Laboratorio de Comunicaciones Celulares, Centro de Estudios Moleculares de la Célula (CEMC), Facultad \\ de Medicina, Universidad de Chile, Santiago, Chile \\ ${ }^{2}$ Department of Surgery, Hospital Clínico José Joaquin Aguirre, Universidad de Chile, Santiago, Chile \\ ${ }^{3}$ Department of Basic and Communitarian Sciences, Faculty of Dentistry, Universidad de Chile, Santiago, Chile \\ ${ }^{4}$ Faculty of Health Sciences, Universidad de Talca, Talca, Chile
}

\begin{abstract}
Caveolins are a family of membrane proteins required for the formation of small plasma membrane invaginations called caveolae that are implicated in cellular trafficking processes. In addition to this structural role, these scaffolding proteins modulate numerous intracellular signaling pathways; often via direct interaction with specific binding partners. Caveolin-1 is particularly well-studied in this respect and has been attributed a large variety of functions. Thus, Caveolin-1 also represents the best-characterized isoform of this family with respect to its participation in cancer. Rather strikingly, available evidence indicates that Caveolin-1 belongs to a select group of proteins that function, depending on the cellular settings, both as tumor suppressor and promoter of cellular traits commonly associated with enhanced malignant behavior, such as metastasis and multi-drug resistance. The mechanisms underlying such ambiguity in Caveolin-1 function constitute an area of great interest. Here, we will focus on discussing how Caveolin-1 modulates cell death and survival pathways and how this may contribute to a better understanding of the ambiguous role this protein plays in cancer.
\end{abstract}

Keywords: Caveolin-1, cell death, metastasis, multi-drug resistance, proliferation, tumor suppression.

\section{INTRODUCTION}

\section{Caveolins}

Caveolins are 21-24 kDa membrane-associated proteins that are highly enriched in specialized, 50-100 $\mathrm{nm}$ omega-shaped invaginations of the plasma membrane referred to as caveolae [1]. Importantly, however, caveolae morphology can vary considerably from being flattened out within the plasma membrane, to individual invaginations of the membrane, multivesicular rosette-like structures or even tubule-like structures (see below). This family of proteins includes the three principle members, Caveolin-1, Caveolin-2 and Caveolin-3. Caveolin-1 and Caveolin-2 are present in many cell types and often co-expressed, while Caveolin-3 distribution is far more restricted and essentially limited to muscle and glia cells [2]. Caveolin-1 and -3 form homo-oligomers, and oligomerization is essential for caveolae biogenesis. Double knock-out mice for Caveolins -1 and -3 completely lack caveolae. Caveolin-2 forms hetero-oligomers with Caveolin-1 and requires Caveolin-1 presence for stability. Thus, Caveolin-1 knock-out mice also lack Caveolin-2 [3-5]. While Caveolins are essential, they are not necessarily sufficient for caveolae formation. In the absence of proteins called cavins, the formation of morphologically

*Address correspondence to this author at the Laboratorio de Comunicaciones Celulares, Centro de Estudios Moleculares de la Célula (CEMC), Facultad de Medicina, Universidad de Chile, Av. Independencia 1027, Santiago, Chile; Tel/Fax: 56-2-7382015;

E-mail: aquest@med.uchile.cl detectable caveolae or tubule structures is impaired [69]. In the absence of cavins, Caveolins associate with microdomains of the plasma membrane and persist there as planar caveolae [10].

Caveolins have been attributed multiple roles in cells besides caveolae formation, including vesicle trafficking, endocytosis, cholesterol homeostasis, as well as regulation of signal transduction, gene expression and protein turnover [10-11]. Since much of the information available with respect to these additional roles stems from studies dealing with the isoform Caveolin-1, we will center the rest of our discussion here on this isoform.

\section{Caveolin-1}

The Caveolin-1 sequence harbors a central hydrophobic domain (residues 102-134), which is thought to adopt a hairpin-like conformation that inserts into the inner leaflet of the plasma membrane. Consequently, both carboxy- and amino-termini face the cytoplasm. A modular sequence, referred to as the "Caveolin Scaffolding Domain" (CSD; residues 82-101) is located adjacent to the hydrophobic domain, in the amino-terminal region, and is required for homo- and hetero-oligomerization, as well as for interaction with a plethora of signaling proteins [3]. In the carboxyterminal region, Caveolin-1 contains three palmitoylated cysteine residues that are important for oligomerization, but not localization to caveolae [12-13], as well as a putative WW-like domain (residues 98-132), in analogy to that described for Caveolin-3 [14-15]. 
Two variants of Caveolin-1 referred to as $1 \alpha$ (residues 1-174) and $1 \beta$ (residues 34-174) can be distinguished, which are generated either from alternative transcripts or by alternative initiation from the same transcript $[3,16]$. Both proteins are ascribed different roles in cells. Most notably, Caveolin-1a contains a tyrosine residue in position 14 that is phosphorylated in response to a large number of different stimuli. Often, but not always, non-receptor tyrosine kinases of the Src family are involved and phosphorylation is triggered as part of a so-called stress response [11]. The importance of Caveolin-1 in this context is underscored by the fact that Caveolin-1 knock-out mice display a remarkably reduced ability to regenerate specific tissues like the liver and also a dramatic decrease in life span [17-18]. Rather intriguingly, phosphorylation of Caveolin-1 is also considered highly relevant to cell migration and metastasis (see discussion later on). These examples suggest that Caveolin-1 is also important player in the regulation of signaling in cells.

Indeed, a large number of signaling pathways have been shown to be regulated by Caveolin- 1 and such versatility highlights the importance of this protein and the potential for involvement in many pathologies, including cancer, where Caveolin-1 plays a highly ambiguous role that depends on a variety of factors as will be discussed [19]. An additional complexity is that, Caveolin-1 is found at the plasma membrane and also in other sub-cellular compartments, such as endoplasmic reticulum (ER), Golgi, endosomes, mitochondria and associated with the nucleus [20-22]. Thus, much of the existing confusion related to Caveolin-1 function that will be discussed, likely reflects the fact that it is often unclear which pool of Caveolin-1 is implicated in a specific event.

Initially, Caveolin-1 was proposed to behave as a tumor suppressor, since presence of the protein was associated with inhibition of signaling pathways that favored cell proliferation and viability, while promoting basal or stimuli-induced cell death. Moreover, Caveolin-1 expression was shown to revert characteristics associated with cell transformation and inhibit tumor growth. Conversely, at later stages of tumor progression, Caveolin-1 has been shown to promote tumor cell migration, multi-drug resistance and, therefore its presence correlates with poor patient prognosis. Whether Caveolin-1 elicits one or the other response seems dependent on the tumor type and the cellular context $[11,19]$. In this review, we will focus predominantly on discussing the ability of Caveolin-1 to modulate processes associated with cell death and survival.

\section{The Tumor Suppressor Hypothesis}

Caveolin-1 was first described as a highly tyrosine phosphorylated substrate in Rous sarcoma virustransformed fibroblasts, suggesting a role for the protein in the transformation process [23-25]. Later on, Caveolin-1 mRNA and protein levels were shown to be down-regulated in oncogene-transformed fibroblasts in culture [26] and re-expression of Caveolin-1 was sufficient to revert the transformed phenotype as well as prevent anchorage-independent growth of these cells [27]. In addition, Caveolin-1 down-regulation using antisense oligonucleotides is sufficient to drive NIH3T3 cell transformation [28]. Also, Caveolin-1 expression is reduced in several human tumors, including lung [29], mammary [30], colon [15, 31] and ovarian carcinomas [32], as well as sarcomas [32] and re-expression of Caveolin-1 often (but not always) results in reversal of characteristics associated with the transformed phenotype. Consistent with these results, lung hyperplasia and predisposition to mammary, as well as carcinogen-induced skin hyperplasia and tumor formation are observed in Caveolin-1 knock-out mice $[4-5,33-35]$. These results indicate that Caveolin-1 displays properties and characteristics of a tumor suppressor molecule in a variety of cellular settings. However, data to the contrary is also available (see subsequent section).

Initially, loss of Caveolin-1 in tumors was associated with the observation that the Caveolin-1 gene localizes to the D7S522 locus, a site frequently deleted in human cancers [36]. Generally, however, loss of Caveolin-1 expression in tumors is now thought to occur via epigenetic mechanisms, including DNA methylation, rather than mutational changes. A detailed discussion of such mechanisms, as well as transcriptional pathways controlling Caveolin-1 expression can be found elsewhere [11]. However, a P132L mutation in Caveolin-1 was detected in $16 \%$ of human breast cancer patients analyzed in one study [37]. Rather intriguingly, this mutation results in a protein that acts as a dominant negative by promoting degradation of wild-type Caveolin-1 [38]. Additional mutations have been described in breast cancer since then [39]. Also, Caveolin-1 expression is regulated at the posttranscriptional level in a differential manner by ROS species and subsequent proteasome-mediated degradation [40]. To what extent this might be a relevant mechanism in the tumor environment remains to be established.

In summary, a variety of mechanisms have been described that may contribute to loss of Caveolin-1 without implicating the need for mutations. In conjunction, these posit Caveolin-1 as a nonconventional tumor suppressor protein.

\section{Caveolin-1 in Multi-Drug Resistance and Metastasis}

Caveolin-1 is reportedly also a protein that promotes more aggressive traits in tumor cells, such as metastasis and multidrug resistance. In normal prostate tissue Caveolin-1 is not expressed, but levels increase upon tumor formation in mouse models and human patients [41-44]. Moreover, Caveolin-1 favors metastasis of prostate cancer cells via an autocrine/paracrine mechanism [45-46]. Likewise, Caveolin-1 expression is increased in multi-drug resistant MCF7 breast cancer cells [47] and promotes anchorage-independent survival by preventing anoikis [48-49]. In patients, Caveolin-1 presence is associated with elevated 
metastasis, multi-drug resistance and poorer prognosis [50-52]. Interestingly, Caveolin-1 is associated with polarized distribution of cell signaling components and Caveolin-1 is required for cell polarization and migration in two and three dimensions [53-55]. Additionally, re-expression of Caveolin-1 in lung adenocarcinoma cells is sufficient to promote filopodia formation, cell migration and enhance the metastatic potential of these cells [56]. Furthermore, phosphorylation of Caveolin-1 on tyrosine favors cell migration and anchorage-independent growth via the adaptor protein Grb7 [57].

These observations strongly favor the notion that Caveolin-1 displays traits that cannot be reconciled with its definition as a tumor suppressor. Indeed, Caveolin-1 is known to promote tumor formation and, in prostate cancer, its presence correlates with poor patient prognosis and survival. Indeed, Caveolin-1 expression increases in primary tumors from prostate [44] and certain leukemia derived cell lines [58]. Also, in prostate cancer cells Caveolin-1 presence enhances tumor growth and favors metastasis [41-42, 46, 59]. Importantly, Caveolin-1 expression in tumor samples is not restricted to tissues, like the prostate, where Caveolin-1 levels are low under normal conditions. For example, increased expression is also observed in colon [31] and breast cancer [48, 52,60], cancer cells where tumor development is associated with initial Caveolin-1 loss (see Fig. 1).

A possible explanation for these discrepancies is that Caveolin-1 functions as a tumor suppressor in systems where negative signaling events downstream of Caveolin1 prevail. Alternatively, Caveolin-1-mediated positive signaling is likely to be important in those cases where

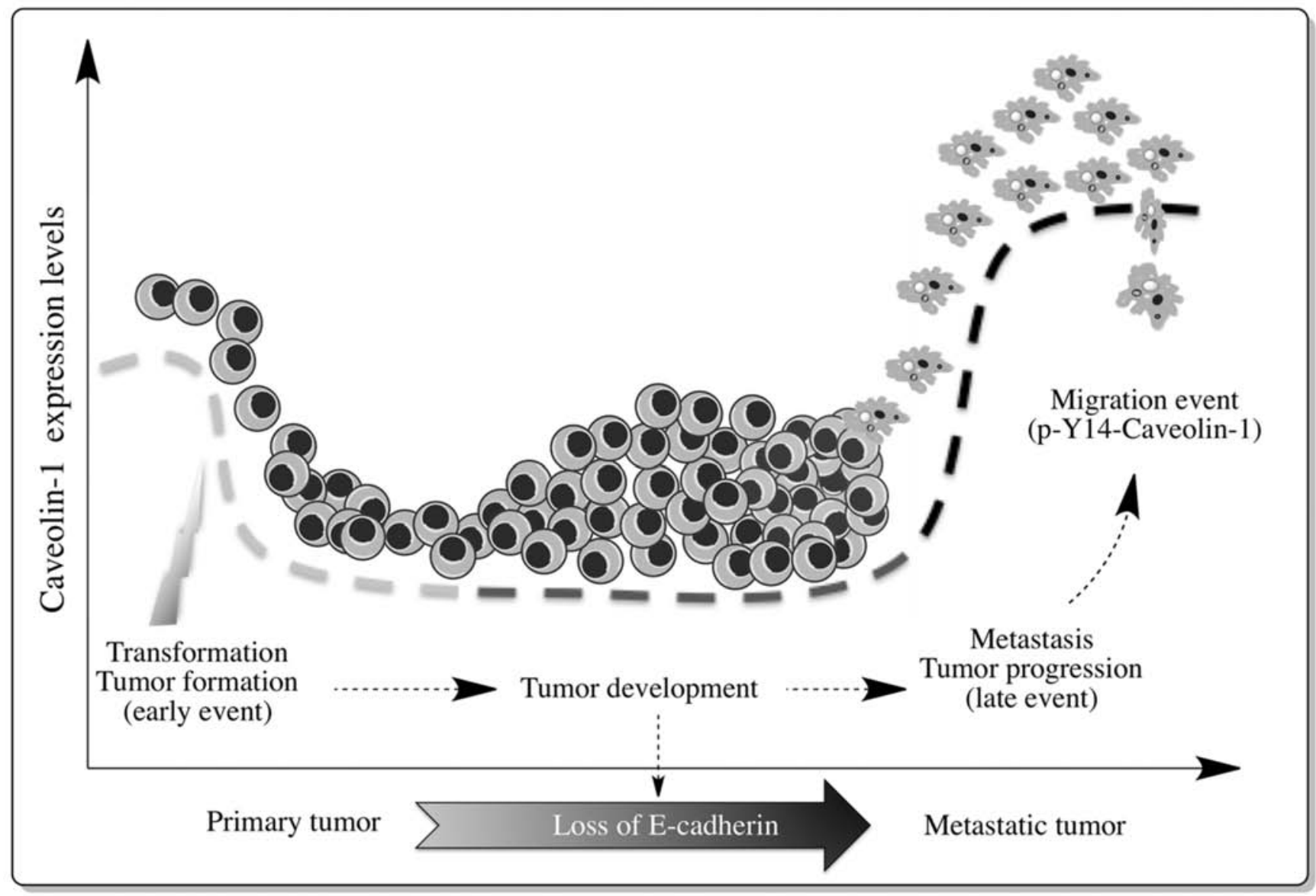

Fig. (1). Dual role of Caveolin-1 in cancer. The ability of Caveolin-1 to participate in events that favor cell proliferation or apoptosis is reflected in the dual role the protein is proposed to play in cancer. In some tissues (breast, lung, colon), consistent with function as a tumor suppressor, Caveolin-1 expression is reduced (light gray dashed line) in the early stages of cell transformation and tumor development. However, as tumors progress, changes occur that generate a "permissive" cellular context. These may include alterations within the cell associated with epithelial-mesenchymal transition, such as the loss of Ecadherin. Alternatively, changes in the tumor cell environment due to inflammation (see text) may also contribute to generating such a "permissive" context. Upon re-expression of Caveolin-1 (black dashed line), triggered by mechanisms that remain to be defined, the protein may develop radically different characteristics (note transition in cell morphology) and promote traits associated with enhanced malignancy (multidrug resistance and metastasis). In this context, phosphorylation of Caveolin-1 on Tyrosine-14 is likely to represent a process that promotes tumor cell migration and enhances metastasis. In other tissues, including prostate, Caveolin-1 is not normally expressed; however, as tumors progress, increased expression may be detected, which is then associated with enhanced tumor cell malignancy, as indicated in the above model. 


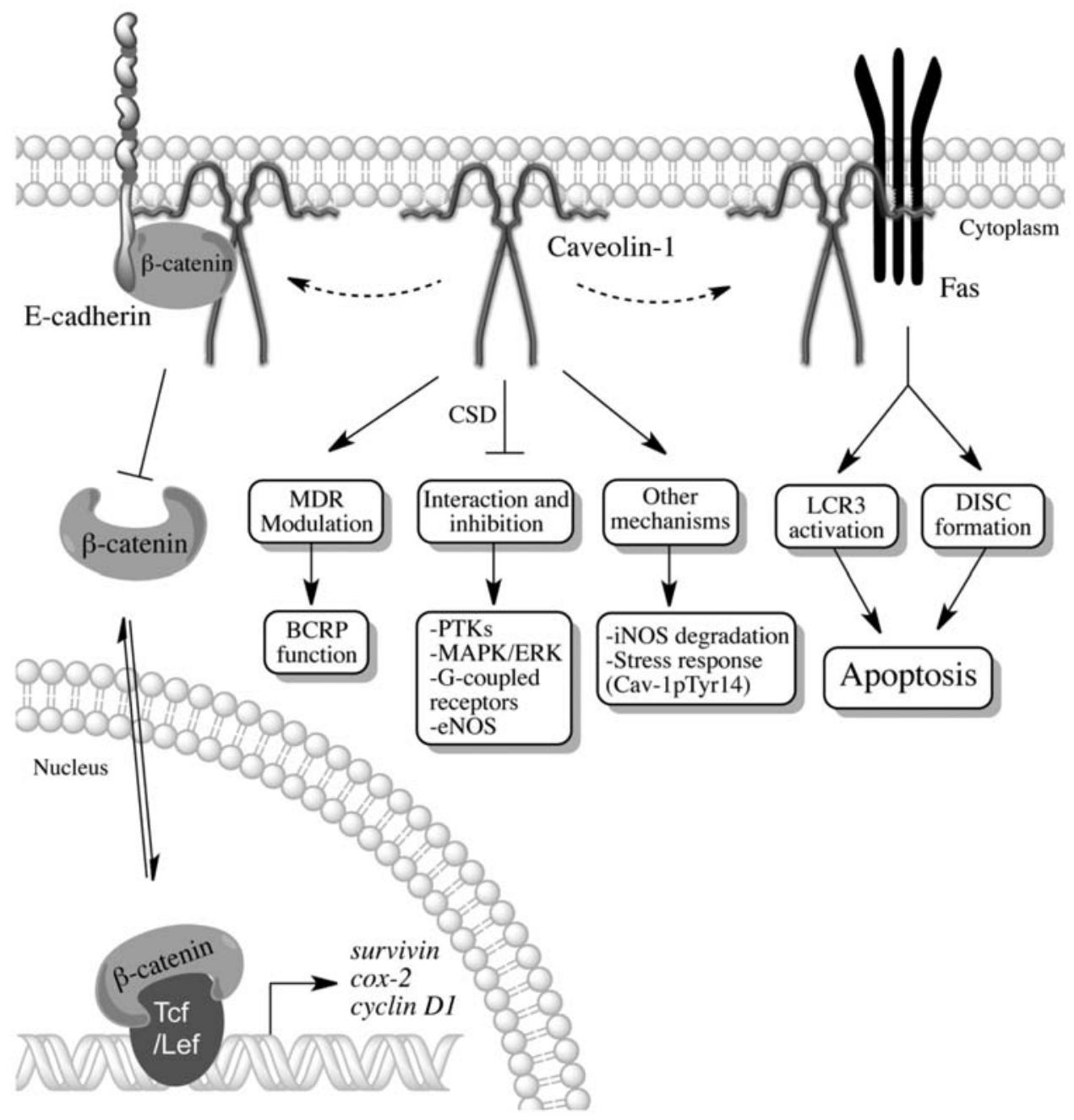

Fig. (2). Schematic showing some of the signaling pathways modulated by Caveolin-1. Caveolin-1 is depicted as a highly versatile molecule that regulates signaling processes both at the transcriptional and post-transcriptional level. To the left, Caveolin-1 is shown to participate in the formation of a multi-protein complex, which includes E-cadherin/ $\beta$-catenin and helps sequester $\beta$-catenin to the membrane, thereby precluding $\beta$-catenin/Tcf-Lef-dependent transcription of genes like Survivin, COX-2 and Cylcin D1. In the center, Caveolin-1 can be seen associating with many different molecules and modulating their function. Some of these interactions involve the CSD and are inhibitory. For others, association may or may not lead to inhibition (MDR modulation). Then again in the section, "Other Mechanisms", interactions with Caveolin-1 may lead to degradation, as is the case for iNOS. Alternatively, phosphorylation of Caveolin-1 on Tyrosine-14 favors interactions and signaling associated with cellular "stress" responses. Finally, to the right some connections between Caveolin-1 and Fas (CD95) are depicted. For details on how these processes relate to the ability of Caveolin-1 to promote cell survival or death, see relevant sections in the text.

presence of the protein is associated with more aggressive tumor behavior. For additional information in this respect, the interested reader may wish to consider previous reviews where such ideas have been discussed extensively $[11,61]$. A corollary to this concept is that Caveolin-1 function as a tumor suppressor is linked to events favoring cell death, while more aggressive tumor behavior is likely to be associated with Caveolin-1dependent mechanisms that favor cell survival. The following discussion in this article will focus on these aspects of Caveolin-1 function.

\section{Caveolin-1-Mediated Control in Signaling}

Caveolin-1 is viewed as a negative regulator in signaling, based on observations linking interaction with Caveolin-1 to subsequent inhibition of target protein function. Many of these interactions, such as those with the epidermal growth factor receptor, Src kinases, the Ras/Raf/MAPK pathway, PKCs and endothelial nitric oxide synthase (eNOS), occur via the scaffolding domain of Caveolin-1 (CSD; amino acids 82-101) and the scaffolding domain binding domain (CBD) found in the respective target proteins [3]. However, as highlighted in Fig. (2), several other modes of action are apparent for Caveolin-1 and association with Caveolin-1 does not necessarily block target protein function.

\section{Other Mechanisms of Post-Transcriptional Control}

Alternative modes of action include enhanced proteasome-mediated degradation of the inducible isoform of nitric oxide synthase (iNOS) via an 
interaction that presumably requires the Caveolin-1 segment 101-135 [62-63]. Phosphorylation of Caveolin1 on Tyr-14 by members of the Src-family kinases, and other tyrosine kinases including the insulin receptor [64-66] permits recruitment of the $\mathrm{COOH}$-terminal Src kinase (Csk), which then phosphorylates Src on residue Y527 favoring intramolecular binding to the $\mathrm{SH} 2$ domain and auto-inhibition of the kinase [67-68]. Since this site is phosphorylated in response to a variety of growth factors (insulin, PDGF, EGF) and stress stimuli, including UV irradiation, mechanical and oxidative stress, as well as hyperosmolarity, phosphorylation of Caveolin-1 on Tyr-14 may constitute an important element in cellular stress responses [6869]. Indeed, although Caveolin-1 knock-out animals are viable and fertile, their ability to respond to specific stress situations, as well as life-span in general is diminished [4-5, 17-18]. Phosphorylation of Caveolin-1 on Tyr-14 is also linked to augmented anchorageindependent growth and cell migration via a Grb7dependent mechanism [57], as well as association with type-I matrix metalloproteinase [70]. Additionally, phosphorylation at this site is considered a crucial event in integrin-regulated membrane microdomain internalization [71-72], as well as EGF-induced caveolae formation [73]. Moreover, presence or absence of this site may account for functionally non-redundant roles ascribed to the two Caveolin-1 isoforms $1 \alpha$ and $1 \beta$ in early vertebrate development [74]. Thus, phosphorylation on Tyr-14 is clearly relevant to Caveolin-1 function in a number of settings; however, the responses associated with this event are highly variable.

\section{Mechanisms of Transcriptional Control}

Caveolin-1 promotes cell cycle arrest via a p53/p21Waf1Cip1-dependent pathway [75]. Also Caveolin-1 enhances premature senescence in primary murine fibroblasts [76]. Oxidative stress-induced senescence involves augmented Caveolin-1 expression via p38 MAPK activated Sp1-dependent transcription [77]. Caveolin-1 expression and intracellular distribution depend on cell-cell adhesion in a manner related to that observed for $\beta$-catenin [78-79]. Indeed, studies have now implicated Caveolin-1 as a negative regulator of $\beta$-catenin-Tcf/Lef-dependent transcription [28, 8081]. Although it remains unclear whether the interaction between Caveolin-1 and $\beta$-catenin is direct or indirect, recruitment of $\beta$-catenin to caveolae and/or Caveolin-1containing protein complexes at the cell surface is thought to preclude $\beta$-catenin Tcf/Lef-dependent transcription of target genes [28, 81-82]. Specifically, Caveolin-1 is suggested to promote cell cycle arrest in $\mathrm{G}_{0} / \mathrm{G}_{1}$ and decrease the number of cells in $\mathrm{S}$ phase by decreasing Cyclin D1 expression [75, 83]. More recently, work from our group has shown that expression of the Inhibitor of Apoptosis (IAP) protein Survivin and also cyclooxygenase-2 (COX-2) are down-regulated by Caveolin-1 in a $\beta$-catenin-Tcf/Lefdependent manner [81-82]. Interestingly, reduction of survivin expression has been associated with enhanced sensitivity to anti-cancer drugs [84].
Moreover, reduction of Survivin expression provides an explanation for several alterations caused by the presence of Caveolin-1, including a decrease in the number of cells in $\mathrm{G}_{2} \mathrm{M}$ and an increment in the susceptibility to apoptosis [81]. Consistent with these observations, the absence of Caveolin-1 in vivo in knock-out mice leads to hyper-proliferation and enhanced $\beta$-catenin-Tcf/Lef signaling in both intestinal crypts and mammary gland stem cells [85-86].

\section{Caveolin-1-Dependent Mechanisms that Modulate Cell Proliferation and Survival}

Caveolin-1 has long been implicated in cell death, either by sensitizing to or directly inducing apoptosis. A variety of possible mechanisms have been associated with such Caveolin-1 functions in cells. Initially, many were linked to the idea that Caveolin-1 binds to and inhibits crucial constituents of cell survival pathways, thereby favoring mitochondrial permeability and caspase activation. Some examples involving CSDCBD interactions, as well as others are summarized below with a focus on the pathways Ras/Raf/ERK, $\mathrm{PI3K} / \mathrm{Akt}$, and $\mathrm{Wnt} / \mathrm{\beta}$-catenin and their role in cell death or survival.

\section{The Ras/Raf/ERK Connection}

Strong links between Caveolin-1 and the MAPK/ERK pathway were established early on in oncogenically transformed fibroblasts, where Caveolin1 expression is lost or diminished [26] and upon re-expression of Caveolin-1 cell transformation is reversed. In Ras-transfromed fibroblasts, this correlates with substantially reduced MAPK/ERK signaling and augmented apoptotic cell death [27]. In NIH3T3 fibroblasts, down-regulation of Caveolin-1 using specific siRNA is sufficient to hyperactivate the MAPK/ERK pathway and induce cell transformation [78]. Also, in Caveolin-1 knock-out mice, signaling via the MAPK/ERK pathway is increased and associated with increased sensitivity to topically applied carcinogens, cardiac hypertrophy and neointimal hyperplasia [33, 87-88]. Moreover, in human head and neck squamous cell cancer, Caveolin- 1 inhibits the ERK pathway and cell growth [89], and in human laryngeal carcinoma cell lines, Caveolin-1 interaction with the EGFR is associated with reduced MAPK/ERK phosphorylation and increased apoptotic cell death [90].

Alternatively, chronic airway diseases, including asthma, are associated with increased airway smooth muscle (ASM) mass, likely due to enhanced proliferation. In ASM cells, down-regulation of Caveolin-1 using siRNA leads to spontaneous MAPK/ERK activation and increased proliferation in the absence of mitogens. Moreover, PDGF stimulation reversed the ability of Caveolin-1 to inhibit MAPK/ERK signaling [91]. Taken together, Caveolin-1-mediated inhibition of the MAPK/ERK pathway appears to preclude inappropriate cell proliferation and also promote cell death. 


\section{The PI3K/Akt Connection}

The Phosphatidylinositol 3-kinase (PI3K)/Akt pathway is an important signaling pathway activated by growth factors that is involved in growth control and cell survival [92-95]. Interestingly, PI3K has been found in caveolae fractions in different cells, including fibroblasts, endothelial cells, and myeloid-derived cells [96] and, consistent with a role as a tumor suppressor, Caveolin-1 has been suggested to inhibit PI3K activity [97]. In a cellular context, this may also involve stabilizing the tumor suppressor phosphatase PTEN [98].

Strangely, however, Caveolin-1 reportedly sensitizes L929 fibrosarcoma, HEK293 and Hela cells to TNFa, staurosporine, $\mathrm{H}_{2} \mathrm{O}_{2}$ and arsenite [99-100] via PI3K/Akt activation, possibly via a ceramide-mediated mechanism [100]. The latter finding is unexpected since Caveolin-1 also has been shown to promote ceramide-dependent cell death via PI3K/Akt activation [101]. Moreover, upon inhibition of PI3K/Akt with inhibitors, like LY-294002 or wortmannin, survival of TNF- $\alpha$-treated L929 cells is substantially improved. Similar effects are also seen in HEK293 and HeLa cells. Thus contrary to the general view, Caveolin- $1 \alpha$ is required for TNF- $\alpha$-induced cell death in L929 cells, and this effect is dependent on activation of a PI3K/Akt signaling pathway [99]. See data summarized in the Table 1.

These examples suggest that Caveolin-1dependent regulation of the PI3K/Akt pathway and also PTEN play a significant role in modulating cell survival, although the precise consequences of Caveolin-1 interaction with this pathway appear to vary quite dramatically.

\section{The $\beta$-Catenin/Tcf-Lef Connection}

As mentioned, results from several laboratories including our own, implicate Caveolin-1 in the regulation of a significant number of $\beta$-catenin/Tcf-Lef target genes, including Cyclin D1, Survivin and COX-2. In doing so, the presence of Caveolin-1 modulates parameters associated with cell proliferation and cell death. Interestingly, however, while Caveolin-1mediated suppression of Survivin was observed in a variety of different cell lines available in the laboratory [81], there were notable exceptions. Specifically, expression of Caveolin-1 in a sub-line derived from the human adenocarcinoma cell line HT29, termed HT29(US), that was obtained by selection for higher metastatic potential, did not alter Survivin expression or cell proliferation. Since loss of E-cadherin is often associated with metastasis, we asked whether the absence of E-cadherin might be linked to the inability of Caveolin-1 to regulate Survivin. Indeed, E-cadherin levels are reduced in HT29(US) cells, as compared to HT29 cells obtained from ATCC, referred to as HT29(ATCC) cells. Furthermore, re-expression of Ecadherin is sufficient to restore the ability of Caveolin-1 in HT29(US) cells to sequester $\beta$-catenin to the plasma membrane, inhibit Survivin expression and control cell proliferation [82, 102]. Similar results were obtained in metastatic murine melanoma B16-F10 cells, where the simultaneous expression of Caveolin-1 with E-cadherin not only reduced significantly proliferation but also enhanced cell death [102]. Taken together, these results indicate that loss of E-cadherin, as is frequently observed during metastasis, provides a molecular understanding of how Caveolin-1 function can switch in a cell context-dependent fashion from functioning as a tumor suppressor to promoting characteristics associated with more malignant tumor cell behavior (see Fig. 1).

Enhanced expression of COX-2 is also frequently observed in human cancers and, as for Survivin, augmented presence is associated with increased tumor cell survival. Indeed, due to its known role in carcinogenesis, angiogenesis and apoptosis, COX-2 has been proposed as a good target for the development of chemopreventive and anti-cancer drugs [103]. Our studies also revealed that Caveolin-1 reduces COX-2 expression via a $\beta$-catenin/Tcf-Lef-dependent transcriptional mechanism. Interestingly, accumulation of prostaglandin E2 $\left(\mathrm{PGE}_{2}\right)$ in the medium of cancer cells is reduced by Caveolin-1 expression and exogenous addition of $\mathrm{PGE}_{2}$ to cells is sufficient to revert Caveolin-1-mediated effects. Thus, on the one hand Caveolin-1 presence interrupts a potent feed-forward amplification loop involving the COX-2-PGE 2 axis and downstream activation of $\beta$-catenin/Tcf-Lef-dependent transcription of genes, including COX-2 itself, as well as Survivin, which promote cell survival and proliferation. Alternatively, the observation that exogenous $\mathrm{PGE}_{2}$ reverts Caveolin-1 mediated suppression of $\beta$-catenin/Tcf-Lef-dependent transcription, even in the presence of E-cadherin, indicates that Caveolin1 -functions associated with its potential role as a tumor suppressor are "conditional" and depend on the cellular environment. In a pro-inflammatory context, where molecules like $\mathrm{PGE}_{2}$ are present, the ability of Caveolin-1 to function in this sense is limited. Finally, the results indicate that Caveolin-1-function in any given cell is not only determined by existing constraints within the same cell, but is also subject to modulation by ongoing processes in neighboring cells.

\section{Caveolin-1 and Apoptosis}

As discussed in previous sections, Caveolin-1 impacts on cell survival pathways in a number of ways that ultimately may predispose to or even directly promote cell death. In this section, we will focus on a few select examples where direct connections to either the extrinsic or intrinsic cell death pathways are apparent.

Binding of ligands to the appropriate death receptors, induces receptors aggregation and caspase8-, followed by caspase-3/7 activation, leading to cell death via the extrinsic pathway [104]. A potential Caveolin-1 binding motif $\left(\mathrm{G}_{53}\right.$ LHHDGQFCH) was identified in the human death receptor Fas sequence and, in a model of lung epithelial apoptosis induced by hyperoxia, Caveolin-1 and Fas colocalization as well as interaction were followed by Fas multimerization and 
Table 1. Caveolin-1 Expression Favors Cell Death and Decreases Proliferation

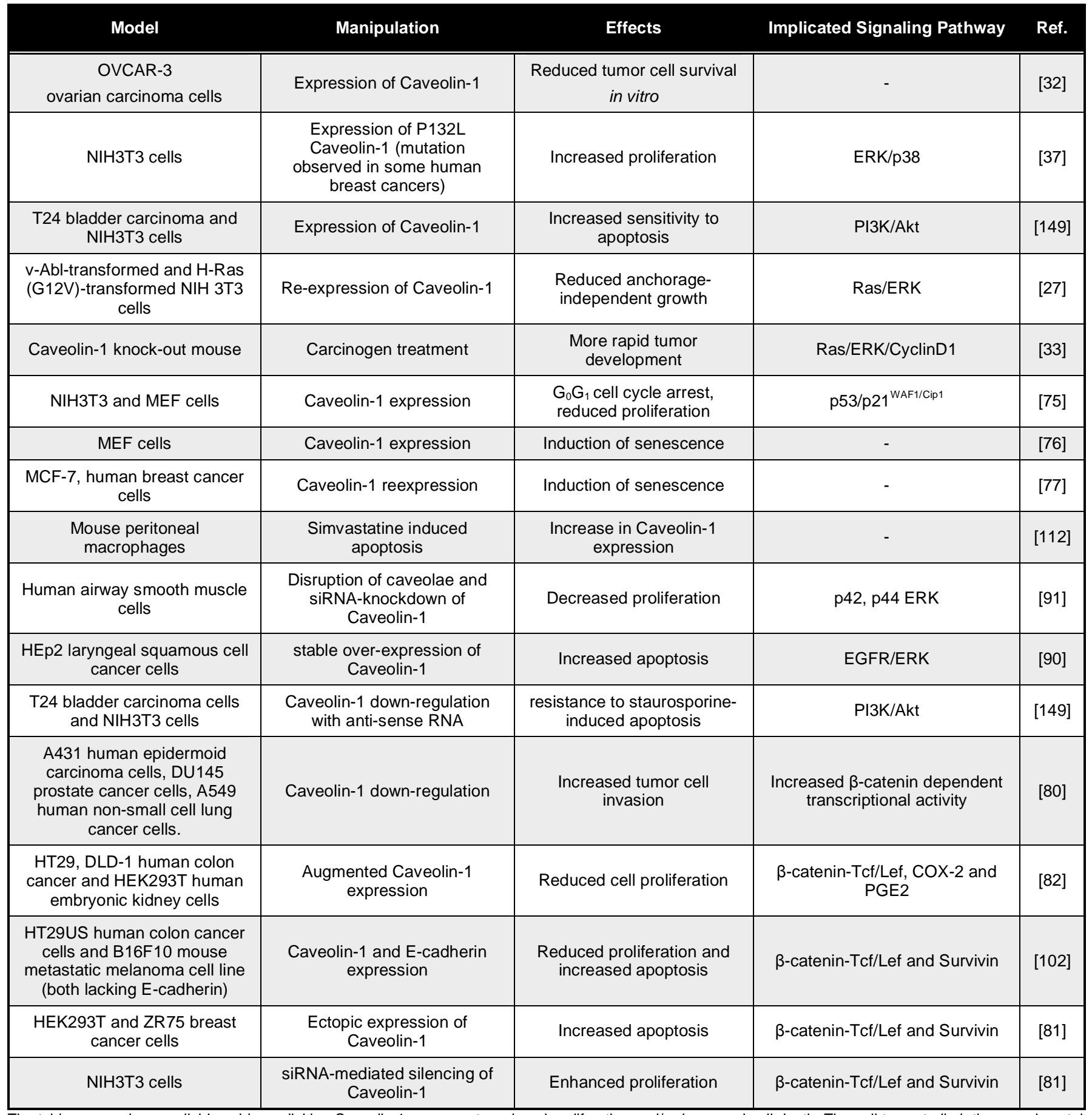

The table summarizes available evidence linking Caveolin-1 presence to reduced proliferation and/or increased cell death. The cell type studied, the experimental approach used to manipulate Caveolin-1 levels, the effects observed, the signaling pathways involved and the corresponding references are indicated (see text for details).

Death-Induced Signaling Complex (DISC) formation. In this context, Caveolin-1-dependent Fas receptor aggregation and the efficiency of BID cleavage required Fas palmitoylation. The absence of Caveolin-1 in deficient cells (Cav-1-/-) disrupted DISC formation. Moreover, mutation of Tyrosine-14 (Y14F) disrupted hyperoxia-induced interaction between BID and Caveolin-1, decreased tBID formation and increased resistance to hyperoxia-induced apoptosis [105].
Recently, Autophagic microtubule-associated protein 1 light chain 3B (LC3B) has been studied as a regulator of lung cell death. In epithelial cells, LC3B forms a complex with the death receptor Fas in lipid rafts, which requires the presence of Caveolin-1. The different complexes, Fas-LC3B, Fas-Caveolin-1 and the Caveolin-1-LC3B were observed in epithelial cells under basal conditions; however, these complexes dissociated rapidly after cellular treatment with cigarette smoke. LC3B knockdown reduces DISC 
formation, in epithelial cells. Therefore, in this model, Fas is sequestered by Caveolin-1 and thus regulates the extrinsic apoptosis pathway. Additionally, LC3B is proposed also to sequester Fas in the basal state. Hence, the net effect of LC3B expression is proapoptotic during cigarette smoke exposure [106-107].

Caveolin-1 is also implicated in regulating the intrinsic apoptosis pathway via studies that establish a connection with acetylcholinesterase (AChE). Previously, AChE activity was found to increase in various types of apoptotic cells [108] and pharmacological inhibition of AChE, as well as antisense RNA-mediated down-regulation of AChE prevented apoptosis. At the onset of apoptosis, AChE was found in the cytoplasm and then, upon commitment to cell death, the enzyme accumulated in the nucleus and in apoptotic bodies [108-109]. Moreover, AChE interacts with Caveolin-1 during apoptosis in events that precede apoptosome formation. While AChE plays a crucial role in promoting oligomerization of Apaf-1, Caveolin-1 appears neither to interact with cytochrome $C$ nor with Apaf-1 [110].

Apoptosis of macrophages is considered important for determining the efficiency of immune responses. Treatment of isolated macrophages activated in vivo in mice with apoptosis-inducing agents lead to a dramatic increase in Caveolin-1 levels while Caveolin-2 is not affected. Phosphatidylserine (PS) externalization is considered a defining feature associated with apoptosis [111]. Interestingly, Caveolin-1 is present in lipid rafts and colocalizes with PS at the cell surface of apoptotic macrophages, where it is suggested to be involved in the efficient externalization of PS [112]. Taken together, these observations link Caveolin-1 directly to the regulation of mechanisms that are relevant to the execution of both the extrinsic and intrinsic apoptosis pathways.

\section{Caveolin-1 - Mediated Survival Mechanisms}

As mentioned, Caveolin-1 was initially implicated as an "oncosupressor" that blocks pathways relevant to cell transformation. Meanwhile, however, it has become clear that Caveolin-1 may also promote signaling events that favor cell survival [113-114]. In this section, we will focus on discussing such events.

The down-regulation of Caveolin-1 in $\mathrm{H} 9 \mathrm{C} 2$ rat cardiomyoblasts with Cav-1-siRNA reduces significantly Insulin-like Growth Factor-I Receptor (IGFIR) tyrosine phosphorylation and Akt activation after IGF-I stimulation and, in these cells, IGF-I was unable to prevent serum withdrawal-induced apoptosis [115]. In endothelial HUVECs, Caveolin-1 down-regulation inhibits IGF-I and insulin-induced activation of eNOS (endothelial nitric oxide synthase), an anti-apoptotic factor in these cells [116]. Moreover, Caveolin-1 seems to play a pro-survival role in prostate cancer cells by promoting PI3K/Akt signaling. Caveolin-1 binds to and inhibits the serine/threonine protein phosphatases PP1 and PP2A, leading to higher PDKI, Akt and ERK1/2 activities and a decrease in thapsigargin-induced apoptosis in the human prostate cancer cell line
LNCaP [117]. Also, the over-expression of Caveolin-1 protects against c-myc-stimulated apoptosis in $\mathrm{LNCaP}$ cells [118] and loss of Caveolin-1 favors apoptosis of prostate tumor cells in a transgenic adenocarcinoma mouse prostate (TRAMP) model [119]. Moreover, physical interaction between Caveolin-1 and the putative oncogene Inhibitor of differentiation/DNA binding (ID-1) plays an essential role in the epithelialmesenchymal transition, cell migration and resistance to taxol-induced apoptosis in the human prostate cancer cell lines LNCaP and 22RV1. Again, the observed anti-apoptotic effects depend on the PI3K/Akt pathway [120].

Anti-apoptotic functions of Caveolin-1 also have been reported in others cell types. In primary cortical neurons from neonatal rats, the expression of Caveolin-1 protects from ischemic cell death induced via stimulation of the $\mathrm{N}$-methyl-D-aspartate receptor (NMDAR). In these cells, Caveolin-1 is thought to favor the correct localization of the NMDAR/Src tyrosine kinase family/ERK signaling components [121]. In lymphoblastoid TK6 cells, expression of Caveolin-1 protected against UV irradiation-induced apoptosis, as well as promoted proliferation after this insult [122] and knock-down of Caveolin-1 with siRNA sensitized human ductal adenocarcinoma cells to ionizing radiation [123]. Besides, NO-induced resistance to anoikis mediated by Caveolin-1 in human lung carcinoma NCl-H4060 cells and over-expression of Caveolin-1 protects against detachment-induced apoptosis [124]. Over-expression of Caveolin-1 in HepG2, a hepatocellular carcinoma cell line, protects from serum deprivation-induced apoptosis, and also enhances migration and invasion by up-regulating MMP-2, MMP-9 and VEGF expression, suggesting that Caveolin-1 could be a critical pro-survival factor in hepatocellular cancer [125]. High glucose levels induce apoptosis in HLE-B3, a lens epithelial cell line, and this effect is observed concomitant with a decrease in Caveolin-1 expression. Upon simvastatin (3-hydroxy-3methylglutaryl coenzyme A inhibitor) or EGF addition to HLE-B3 cells cultured to high glucose-medium, expression of Caveolin-1 increases while apoptosis decreases [126]. Interestingly, Caveolin-1 has been found to prevent oxidative damage in human SK-N-MC neuroblastoma cells. The populations of DAF-2DApositive (NO producers) and Annexin V-positive cells were remarkably reduced by cell treatment with the CSD (Caveolin-1 scaffolding domain) peptide and Caveolin-1 transfection, but not by CSC, scrambled control peptide, or transfection with an empty vector. Indeed, in this study hypoxia activated iNOS and promoted NO production, resulting in an up-regulation of Caveolin-1 expression. This increase protected neuroblastoma cells against oxidative injury by inhibiting iNOS expression and NO production. The results suggest that up-regulation of Caveolin-1 in response to hypoxia may serve to prevent oxidative injury in neuroblastoma cells [127].

Here it is important to note that Caveolin-1 not only protects from apoptosis by enhancing anti-apoptotic signaling in cell lines, but reportedly also plays a similar 
role in normal cell physiology. Indeed, the absence of Caveolin-1 in knock-out mice induces cell damage and apoptosis in thyrocytes. In this case, the absence of Caveolin-1 leads to thyrocyte dysfunction, excessive oxidative stress and then finally cell death [128]. Also, genetic ablation of Caveolin-1 in mice increases the volume of cerebral ischemia due to impaired angiogenesis of vascular endothelial cells, whereby the expression of Caveolin-1 appears to be necessary to increase the protein levels of eNOS after an ischemic insult [129].

In summary, these reports suggest that besides its well documented pro-apoptotic role, Caveolin-1 also acts as an anti-apoptotic and pro-survival factor in various cell types, whereby several possible mechanisms appear to be involved. Thus, as already mentioned, Caveolin-1 plays a highly ambiguous role in the regulation of cell survival and proliferation pathways, whereby the observed outcomes appear to depend largely on the cell context.

\section{Caveolin-1 and Drug-Resistance}

Chemotherapy is one of the most frequently used treatments against cancer. Unfortunately, cancer cells often adapt to this challenge by becoming resistant, thereby avoiding drug-induced cell death [130]. Several reports suggest that Caveolin-1 participates as an important mediator of drug-resistance in cancer cells. In patients, up-regulation of Caveolin-1 levels is frequently observed in advanced stages of lung [51, 131], prostate [42, 44], breast [44], pancreas [132] and renal cancer [133]. In these cases, Caveolin-1 is associated with poor patient prognosis and reduced patient survival. Moreover, in lung cancer patients, Caveolin-1 expression is inversely correlated with responses to gemcitabine, since absence of Caveolin-1 expression is associated with increased responsiveness to therapy and patient survival. These observations provide strong evidence favoring the notion that Caveolin-1 presence is associated with the development of drug-resistance [51].

These clinical data are complemented by findings in cell lines that correlate enhanced Caveolin-1 with the development of drug resistance. In colon cancer cells, selection for methotrexate resistance is associated with increased Caveolin-1 expression [31, 134]. Interestingly, in HT29 cells siRNA-mediated Caveolin-1 down-regulation reduces cell viability after metothrexate exposure [134]. Similar increases in Caveolin-1 levels are observed in colchicine-resistant HT29 colon cancer and adriamycin-resistant MCF7 breast cancer cells. In these cell lines, Caveolin-1 expression increased together with Caveolin-2 and glucosylceramide cell content. These changes were independent of P-glycoprotein expression, indicating that the observed changes in Caveolin-1 are not the consequence of P-glycoprotein induction [47]. Furthermore, in lung cancer cells augmented Caveolin1 expression is detected after chronic etoposide exposure [135] and acute bleomycin treatment [136]. In both cases, augmented Caveolin-1 expression correlated with cell survival [135-136]. In addition, augmented Caveolin-1 expression is observed in taxol and epothilone-resistant A549 cancer cells [43]. In this case, Caveolin-1 upregulation occurred in the absence of changes in P-glycoprotein [43]. Furthermore, in Ewing's sarcoma cells incubated with doxorubicin an increase in Caveolin-1 levels is detected. In this case augmented Caveolin-1 expression is related to reduced doxorubicin-induced cell death [137]. In metastatic prostate cancer cells, unlike other cancers, higher Caveolin-1 protein levels are frequently observed. In this case, Caveolin-1 has been proposed as a metastasis gene, which participates in androgen resistance $[59,138]$. As mentioned, in prostate cancer cells, Caveolin-1 mediated inhibition of apoptosis is associated with the transcription factor Id-1 (for inhibitor of differentiation and DNA binding). Caveolin-1 interaction with ld-1 increased $\mathrm{Bcl}-2$ and prevented taxol-mediated induction of apoptosis by decreasing caspase- 3 and PARP cleavage [120]. Taken together, these data strongly suggest that increased Caveolin- 1 levels in cancer cell lines favors the development of the multidrug-resistant phenotype in a manner apparently unrelated to the presence of P-glycoprotein.

Given the significance of augmented Caveolin-1 expression in advanced stages of cancer and the association there with multidrug resistance, it is tempting to speculate that Caveolin-1 presence favors mechanisms which help avoiding cell death. Indeed, in a mouse model of metastatic prostate cancer, antisense mediated Caveolin-1 knock-down, enhanced sensitivity to androgen withdrawal. Interestingly, antisense mediated decreases in Caveolin-1 levels also reduced prostate tumor volume and increased cell death and this effect was lost when mice were injected with testosterone. In vitro, in prostate cancer cells, Caveolin-1 specific anti-sense constructs induce cell death after testosterone removal. This effect was abrogated, when the cells were treated with the general caspase inhibitor Z-VAD-FMK [139]. Additionally, in human prostate cancer cells, Caveolin-1 presence favors phenylephrine-induced resistance to thapsigargin mediated cell death. This Caveolin-1dependent effect is characterized by reduced caspase3 activation and PARP cleavage in a Bax dependent fashion [140]. In addition, in renal cancer cells, Caveolin-1 is up-regulated after chronic treatment with doxorubicin. siRNA treatment against Caveolin-1 reduces cell survival and activates the proapoptotic proteins PARP and Bax and reduces anti-apoptotic Bcl2 after doxorubicin treatment. These results point towards an anti-apoptotic role for Caveolin-1 in these cells. Also, pulmonary metastasis was reduced in SCID-mice injected with Caveolin-1 siRNA-transfected cells treated with doxorubicin, suggesting again that Caveolin-1 reduces sensitivity to chemotherapeutic agents both in vitro and in vivo [141]. Finally, Caveolin1 knock-down in MDCK cells over-expressing the drug transporter protein BCRP (for breast cancer resistance protein) sensitizes the cells to the chemotherapeutic agent mitoxantrone, thus reducing cell proliferation [142]. Altogether, these results indicate that Caveolin-1 
participates significantly in facilitating the development of multidrug resistance. Thus, drugs that eliminate or reduce Caveolin-1 levels are expected to sensitize cells to drug-induced death.

\section{Mechanisms of Caveolin-1-Mediated Drug Resistance}

The main transporters involved in the development of drug-resistance, predominantly as a consequence of over-expression, are P-glycoprotein and BCRP. Both belong to the $A B C$ transmembrane transporter family that, in an energy-dependent fashion, transport drugs to the cell exterior, thereby reducing the effective intracellular concentration. Some anticancer-drugs that are known substrates for P-glycoprotein and BCRP include anthracyclines, topoisomerase inhibitors, taxanes and mitoxantrone among others [130]. Interestingly, a tight association has been noted between Caveolin-1 and P-glycoprotein. Indeed, both proteins co-distribute in the same detergent-resistant membrane fractions $[47,135,143]$, and coimmunoprecipitate in brain capillaries, rat brain endothelial, chinese hamster ovary and breast cancer cells [143-145]. This interaction appears to be mediated by the presence of a Caveolin-1-binding motif in P-glycoprotein [143]. In addition, both Caveolin-1 and the MDR gene are co-expressed in normal and leukemia cells obtained from human patients [146]. However, despite these findings some groups have obtained evidence showing that Caveolin-1 represses P-glycoprotein function in brain-derived endothelial cells and breast cancer cells [145, 147]. Therefore, the role of Caveolin-1 interactions with P-glycoprotein and their consequences for P-glycoprotein activity remain controversial. However, as suggested in the previous sections, the ability of Caveolin-1 to promote drugresistance does not appear to be linked to P-glycoprotein expression.

Additionally, Caveolin-1 function in this context has been linked to another ABC transporter, the BCRP protein, since it was shown that Caveolin-1 co-distributes with BCRP in detergent-resistant membrane fractions and interacts there with BCRP $[142,148]$. Interestingly, in Caveolin-1 knock-down cells, BCRP activity was reduced and the cells became more sensitive to mitoxantrone-induced reduction in cell proliferation [142]. These results clearly suggest that Caveolin-1 presence promotes BCRP function, although, at the molecular level, it remains unclear how this occurs.

Recently, an alternative mechanism was put forward to explain how Caveolin-1 presence may facilitate multi-drug resistance and protect against cell death. In sarcoma cells, Caveolin-1 expression is associated with protection against doxorubicin-induced cell death. Indeed, re-expression of Caveolin-1 in cells in which Caveolin-1 had previously been silenced lead to a reduction in apoptosis after doxorubicin treatment. Importantly, loss of Caveolin-1 correlated with a reduction in the active, phosphorylated form of protein kinase $\mathrm{C} \alpha(\mathrm{PKC} \alpha)$. Interestingly, drug-sensitization after Caveolin-1 knock-down was abrogated when PKC $\alpha$ was overexpressed, suggesting that PKC $\alpha$ may act downstream of Caveolin-1 to protect against cell death in drug-resistant cells [137]. Whether PKCa acts in a similar fashion as a downstream effector of Caveolin-1 in other cellular systems remains to be shown. See data summarized in the Table 2.

Taken together, the data discussed strongly suggest that up-regulation of Caveolin-1 is observed in late stages of cancer and in drug-resistant cancer cell lines. Moreover, increased Caveolin-1 expression appears to favor cancer cell survival by preventing apoptotic cell death after exposure to chemotherapeutics agents. Additionally, there is substantial evidence linking Caveolin-1 function to the $A B C$ transporters, P-glycoprotein and BCRP, although the data remain controversial in this respect. Additional experiments are required to clarify this point. Finally, PKCa has emerged as a potential effector molecule that mediates Caveolin-1-dependent protection against cell death in drug-resistant cells. Again, additional experiments are required to confirm the relevance of these observations in other experimental models.

\section{The Two Sides to Caveolin-1: Summary and Outlook}

The literature revisited in this review highlights Caveolin-1 as a protein, which plays a highly ambiguous role in cancer. As depicted in the Fig. (1), Caveolin-1 expression is frequently reduced or suppressed in early stages of cancer, by mechanisms that are not entirely clear, although methylation of CpG-rich islands in the promoter region has been suggested. As might be expected for a tumor suppressor, re-expression of the protein frequently reduces tumor growth in vivo observed for a number of different tumor cell lines. Despite such evidence, Caveolin-1 is also implicated in tumor progression, the development of multi-drug resistance and metastasis. Moreover, presence of the protein in tumors has been associated with poorer patient prognosis. Consistent with such ambiguity in function, this review summarized a considerable amount of data showing that Caveolin-1 can both favor cell proliferation and survival, as well as enhance processes that lead to cell death. While such distinct results may be attributed to use of different experimental systems, some reports suggest that this "switch" in function can occur within the same cell. To resolve this apparent dichotomy, our model proposes that both intracellular and extracellular changes help create a permissive environment. Loss of E-cadherin is highlighted as one possibility, but others include exposure to a pro-inflammatory environment, as was discussed. Hence, when Caveolin-1 is re-expressed, by again poorly defined mechanisms, restraints initially present in the non-transformed cells, no longer exist such that the protein now favors activities associated with more malignant tumor cell behavior. One possibility depicted here is phosphorylation on Tyrosine-14, a modification that is implicated in promoting cell migration and metastasis. To what extent this may contribute to other characteristics, such as multi-drug resistance remains to be defined. Thus, studies related to Caveolin-1 (and a few other select molecules not discussed here) are beginning 
Table 2. Caveolin-1 Expression Favors Cell Survival and/or Proliferation

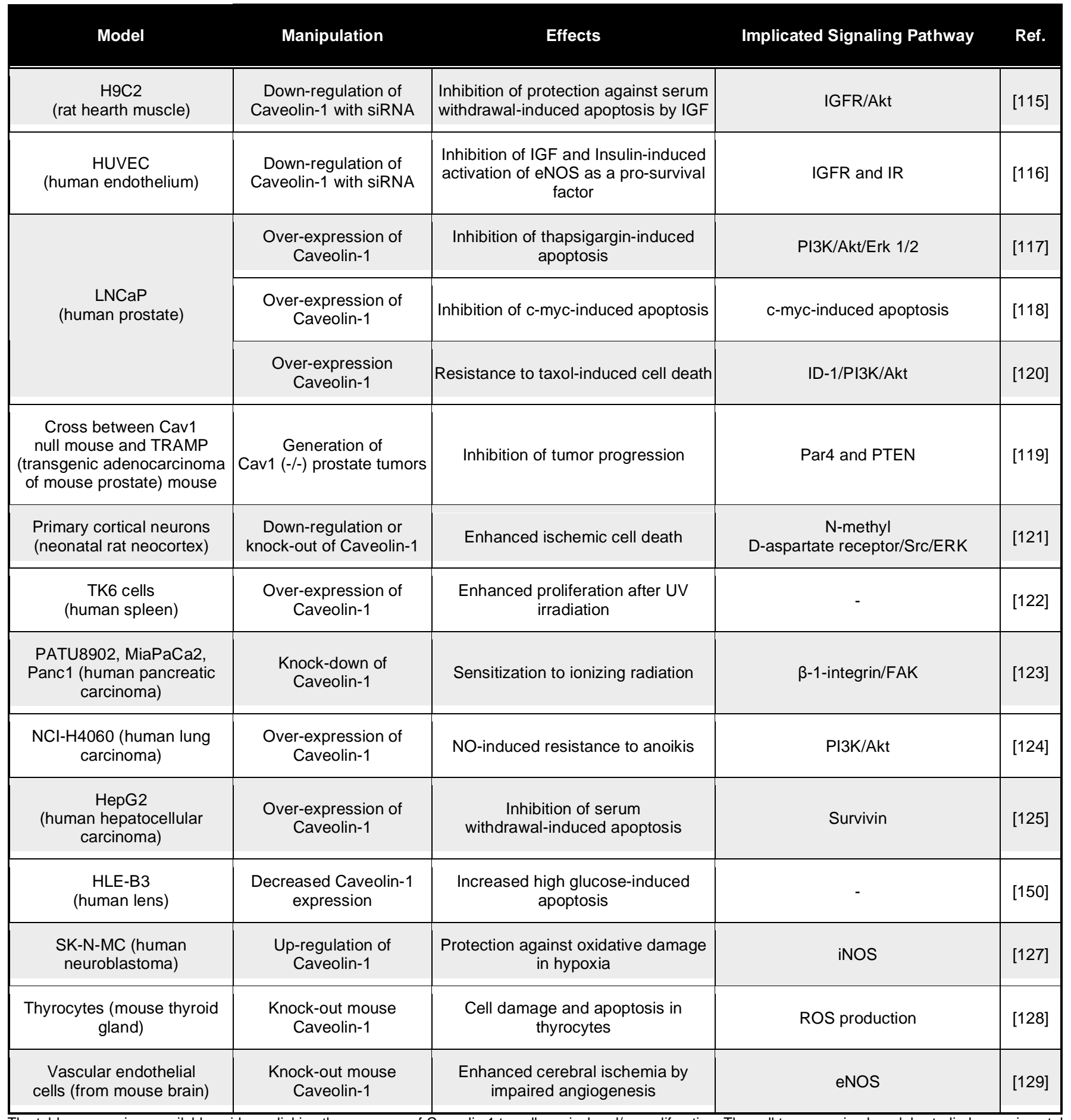

The table summarizes available evidence linking the presence of Caveolin-1 to cell survival and/or proliferation. The cell type or animal models studied, experimental approach used to manipulate Caveolin-1 levels, the signaling pathway involved and the corresponding references are indicated. Information concerning the signaling pathways involve was not always available (see the text for details).

to alter the classic view suggesting that cancer originates as the consequence of mutations in either oncogenes or tumor suppressors. In doing so, they are likely also to alter how we go about treating the disease. As a corollary, a better understanding of Caveolin-1 biology and how function of the molecule changes throughout tumor development can be expected to help in the development of therapeutic strategies that harness its ability to promote cell death in tumor cells without undesired side effects.

\section{ABBREVIATIONS}

$\begin{array}{ll}\text { APC } & =\text { Adenomatous polyposis coli } \\ \text { COX-2 } & =\text { Cyclooxygenase-2 } \\ \text { GSK-3 } & =\text { Glycogen synthase kinase } 3 \\ \text { CSD } & =\text { Caveolin scaffolding domain } \\ \text { CBD } & =\text { Caveolin binding domain }\end{array}$




$$
\begin{array}{ll}
\text { IAP } & =\text { Inhibitor of Apoptosis } \\
\text { eNOS } & =\text { Endothelial oxide nitric synthase } \\
\text { iNOS } & =\text { Inducible oxide nitric synthase } \\
\text { MAPK } & =\text { Mitogen activated protein kinase } \\
\text { PGE2 } & =\text { Prostaglandin E2 } \\
\text { TNFa } & =\text { Tumor necrosis factor alpha } \\
\text { ASM } & =\text { Airway smooth muscle } \\
\text { PI3K } & =\text { Phosphatidylinositol 3-kinase } \\
\text { PTEN } & =\text { Phosphatase and tensin homolog } \\
\text { TCf/Lef } & =\text { Binding element } \\
\text { DISC } & =\text { Death-induced signaling complex } \\
\text { LC3B } & =\text { Protein 1 light chain 3B } \\
\text { AChE } & =\text { Acetylcholinesterase } \\
\text { PS } & =\text { Phosphatidylserine } \\
\text { IGF-IR } & =\text { Insulin-like growth factor-I receptor } \\
\text { PP1 and } & =\text { Serine/threonine protein phosphatases } \\
\text { PP2 } & \text { 1 and } 2, \text { respectively } \\
\text { TRAMP } & =\text { Transgenic adenocarcinoma mouse } \\
\text { NMDAR } & =\text { N-methyl-D-aspartate receptor } \\
\text { MMP-2 and } & =\text { Metalloproteinase } 2 \text { and } 9, \text { respectively } \\
\text { MMP-9 } & \\
\text { Z-VAD-FMK } & =\text { Z-Val-Ala-Asp-fluoromethylketone } \\
\text { PARPs } & =\text { Poly ADP-ribose polymerases } \\
\text { MDR } & =\text { Multidrug resistance } \\
\text { BCRP } & =\text { ATP-binding cassette transporters } \\
\text { PKCa } & =\text { Protein kinase Ca } \\
\text { VEGF } & =\text { Vascular endothelial growth factor } \\
&
\end{array}
$$

\section{CONFLICT OF INTEREST}

The authors declare no conflict of interest.

\section{ACKNOWLEDGEMENTS}

This work was supported by FONDAP 15010006 (AFGQ), FONDECYT 1090071 (AFGQ), FIRCA-NIH 5R03TW007810-3 (LL), FONDECYT 1070699, 1110149 (LL), Iniciativas Científicas Milenio: BNI P09015-F (LL), FONDECYT INICIACION 11100287 (VT), FONDECYT post-doctoral award (31003 DG) and CONICYT and Mecesup PhD Student Fellowships (LLG, CS, SN, AA, JGF).

\section{REFERENCES}

[1] Anderson RG. The caveolae membrane system. Annu Rev Biochem 1998; 67: 199-225.

[2] Tang Z, Scherer PE, Okamoto T, et al. Molecular cloning of Caveolin-3, a novel member of the Caveolin gene family expressed predominantly in muscle. J Biol Chem 1996; 271(4): 2255-61.

[3] Okamoto T, Schlegel A, Scherer PE, Lisanti MP. Caveolins, a family of scaffolding proteins for organizing "preassembled signaling complexes" at the plasma membrane. J Biol Chem 1998; 273(10): 5419-22.

Drab M, Verkade $\mathrm{P}$, Elger $\mathrm{M}$, et al. Loss of caveolae, vascular dysfunction, and pulmonary defects in Caveolin-1 gene-disrupted mice. Science 2001; 293(5539): 2449-52.

Razani B, Engelman JA, Wang XB, et al. Caveolin-1 null mice are viable but show evidence of hyperproliferative and vascular abnormalities. J Biol Chem 2001; 276(41): 3812138.

Liu L, Pilch PF. A critical role of cavin (polymerase I and transcript release factor) in caveolae formation and organization. J Biol Chem 2008; 283(7): 4314-22.

Hill MM, Bastiani M, Luetterforst R, et al. PTRF-Cavin, a conserved cytoplasmic protein required for caveola formation and function. Cell 2008; 132(1): 113-24.

McMahon KA, Zajicek $\mathrm{H}$, Li WP, et al. SRBC/cavin-3 is a Caveolin adapter protein that regulates caveolae function. EMBO J 2009; 28(8): 1001-15.

Hansen CG, Bright NA, Howard G, Nichols BJ. SDPR induces membrane curvature and functions in the formation of caveolae. Nat Cell Biol 2009; 11(7): 807-14.

Lajoie P, Goetz JG, Dennis JW, Nabi IR. Lattices, rafts, and scaffolds: domain regulation of receptor signaling at the plasma membrane. J Cell Biol 2009; 185(3): 381-5.

Quest AF, Gutierrez-Pajares JL, Torres VA. Caveolin-1: an ambiguous partner in cell signalling and cancer. J Cell Mol Med 2008; 12(4): 1130-50.

Dietzen DJ, Hastings WR, Lublin DM. Caveolin is palmitoylated on multiple cysteine residues. Palmitoylation is not necessary for localization of Caveolin to caveolae. J Biol Chem 1995; 270(12): 6838-42.

Monier S, Dietzen DJ, Hastings WR, Lublin DM, Kurzchalia TV. Oligomerization of VIP21-Caveolin in vitro is stabilized by long chain fatty acylation or cholesterol. FEBS Lett 1996; 388(2-3): 143-9.

Sotgia F, Lee JK, Das K, et al. Caveolin-3 directly interacts with the C-terminal tail of beta -dystroglycan. Identification of a central WW-like domain within Caveolin family members. J Biol Chem 2000; 275(48): 38048-58.

Bender F, Montoya M, Monardes V, Leyton L, Quest AF. Caveolae and caveolae-like membrane domains in cellular signaling and disease: identification of downstream targets for the tumor suppressor protein Caveolin-1. Biol Res 2002; 35(2): 151-67.

Kogo H, Aiba T, Fujimoto T. Cell type-specific occurrence of Caveolin-1alpha and -1 beta in the lung caused by expression of distinct mRNAs. J Biol Chem 2004; 279(24): 25574-81.

Park DS, Cohen AW, Frank PG, et al. Caveolin-1 null (-/-) mice show dramatic reductions in life span. Biochemistry 2003; 42(51): 15124-31.

Fernandez MA, Albor C, Ingelmo-Torres M, et al. Caveolin-1 is essential for liver regeneration. Science 2006; 313(5793): 1628-32.

[19] Goetz JG, Lajoie P, Wiseman SM, Nabi IR. Caveolin-1 in tumor progression: the good, the bad and the ugly. Cancer Metastasis Rev 2008; 27(4): 715-35.

[20] Parton RG, Hanzal-Bayer M, Hancock JF. Biogenesis of caveolae: a structural model for Caveolin-induced domain formation. J Cell Sci 2006; 119(Pt 5): 787-96.

[21] Parton RG, Howes MT. Revisiting Caveolin trafficking: the end of the caveosome. J Cell Biol; 191(3): 439-41.

[22] Hayer A, Stoeber M, Ritz D, Engel S, Meyer HH, Helenius A. Caveolin-1 is ubiquitinated and targeted to intralumenal vesicles in endolysosomes for degradation. J Cell Biol 2010; 191(3): 615-29.

[23] Glenney JR, Jr. Tyrosine phosphorylation of a 22-kDa protein is correlated with transformation by Rous sarcoma virus. $J$ Biol Chem 1989; 264(34): 20163-6.

[24] Glenney JR, Jr., Zokas L. Novel tyrosine kinase substrates from Rous sarcoma virus-transformed cells are present in the membrane skeleton. J Cell Biol 1989; 108(6): 2401-8.

[25] Glenney JR, Jr., Soppet D. Sequence and expression of Caveolin, a protein component of caveolae plasma membrane domains phosphorylated on tyrosine in Rous 
sarcoma virus-transformed fibroblasts. Proc Natl Acad Sci USA 1992; 89(21): 10517-21.

[26] Koleske AJ, Baltimore D, Lisanti MP. Reduction of Caveolin and caveolae in oncogenically transformed cells. Proc Natl Acad Sci USA 1995; 92(5): 1381-5.

[27] Engelman JA, Wykoff CC, Yasuhara S, Song KS, Okamoto $\mathrm{T}$, Lisanti MP. Recombinant expression of Caveolin-1 in oncogenically transformed cells abrogates anchorageindependent growth. J Biol Chem 1997; 272(26): 16374-81.

[28] Galbiati F, Volonte D, Brown AM, et al. Caveolin-1 expression inhibits Wnt/beta-catenin/Lef-1 signaling by recruiting beta-catenin to caveolae membrane domains. $\mathrm{J}$ Biol Chem 2000; 275(30): 23368-77.

[29] Racine C, Belanger M, Hirabayashi H, Boucher M, Chakir J, Couet J. Reduction of Caveolin 1 gene expression in lung carcinoma cell lines. Biochem Biophys Res Commun 1999; 255(3): 580-6.

[30] Lee SW, Reimer CL, Oh P, Campbell DB, Schnitzer JE. Tumor cell growth inhibition by Caveolin re-expression in human breast cancer cells. Oncogene 1998; 16(11): 1391-7.

[31] Bender FC, Reymond MA, Bron C, Quest AF. Caveolin-1 levels are down-regulated in human colon tumors, and ectopic expression of Caveolin- 1 in colon carcinoma cell lines reduces cell tumorigenicity. Cancer Res 2000; 60(20): 5870-8.

[32] Wiechen K, Diatchenko L, Agoulnik A, et al. Caveolin-1 is down-regulated in human ovarian carcinoma and acts as a candidate tumor suppressor gene. Am J Pathol 2001; 159(5): 1635-43.

[33] Capozza F, Williams TM, Schubert W, et al. Absence of Caveolin-1 sensitizes mouse skin to carcinogen-induced epidermal hyperplasia and tumor formation. Am J Pathol 2003; 162(6): 2029-39.

[34] Williams TM, Cheung MW, Park DS, et al. Loss of Caveolin-1 gene expression accelerates the development of dysplastic mammary lesions in tumor-prone transgenic mice. Mol Biol Cell 2003; 14(3): 1027-42.

[35] Lin MI, Yu J, Murata T, Sessa WC. Caveolin-1-deficient mice have increased tumor microvascular permeability, angiogenesis, and growth. Cancer Res 2007; 67(6): 2849-56.

[36] Engelman JA, Lee RJ, Karnezis A, et al. Reciprocal regulation of neu tyrosine kinase activity and Caveolin-1 protein expression in vitro and in vivo. Implications for human breast cancer. J Biol Chem 1998; 273(32): 20448-55.

[37] Hayashi K, Matsuda S, Machida K, et al. Invasion activating Caveolin-1 mutation in human scirrhous breast cancers. Cancer Res 2001; 61(6): 2361-4.

[38] Lee H, Park DS, Razani B, Russell RG, Pestell RG, Lisanti MP. Caveolin-1 mutations (P132L and null) and the pathogenesis of breast cancer: Caveolin-1 (P132L) behaves in a dominant-negative manner and Caveolin-1 (-/-) null mice show mammary epithelial cell hyperplasia. Am J Pathol 2002; 161(4): 1357-69.

[39] Li T, Sotgia F, Vuolo MA, et al. Caveolin-1 mutations in human breast cancer: functional association with estrogen receptor alpha-positive status. Am J Pathol 2006; 168(6): 1998-2013.

[40] Luanpitpong S, Talbott SJ, Rojanasakul Y, et al. Regulation of lung cancer cell migration and invasion by reactive oxygen species and Caveolin-1. J Biol Chem 2010; 285(50): 3883240.

[41] Bartz R, Zhou J, Hsieh JT, Ying Y, Li W, Liu P. Caveolin-1 secreting LNCaP cells induce tumor growth of Caveolin-1 negative LNCaP cells in vivo. Int J Cancer 2008; 122(3): 5205.

[42] Karam JA, Lotan Y, Roehrborn CG, Ashfaq R, Karakiewicz $\mathrm{PI}$, Shariat SF. Caveolin-1 overexpression is associated with aggressive prostate cancer recurrence. Prostate $2007 ; 67(6)$ : 614-22.

[43] Yang CP, Galbiati F, Volonte D, Horwitz SB, Lisanti MP. Upregulation of Caveolin-1 and caveolae organelles in Taxolresistant A549 cells. FEBS Lett 1998; 439(3): 368-72.

[44] Yang G, Truong LD, Timme TL, et al. Elevated expression of Caveolin is associated with prostate and breast cancer. Clin Cancer Res 1998; 4(8): 1873-80.
[45] Li WP, Liu P, Pilcher BK, Anderson RG. Cell-specific targeting of Caveolin-1 to caveolae, secretory vesicles, cytoplasm or mitochondria. J Cell Sci 2001; 114(Pt 7): 1397408.

[46] Tahir SA, Yang G, Ebara S, et al. Secreted Caveolin-1 stimulates cell survival/clonal growth and contributes to metastasis in androgen-insensitive prostate cancer. Cancer Res 2001; 61(10): 3882-5.

[47] Lavie Y, Fiucci G, Liscovitch M. Up-regulation of caveolae and caveolar constituents in multidrug-resistant cancer cells. J Biol Chem 1998; 273(49): 32380-3.

[48] Fiucci G, Ravid D, Reich R, Liscovitch M. Caveolin-1 inhibits anchorage-independent growth, anoikis and invasiveness in MCF-7 human breast cancer cells. Oncogene 2002; 21(15): 2365-75.

[49] Ravid D, Maor S, Werner H, Liscovitch M. Caveolin-1 inhibits anoikis and promotes survival signaling in cancer cells. Adv Enzyme Regul 2006; 46: 163-75.

[50] Ando $\mathrm{T}$, Ishiguro $\mathrm{H}$, Kimura $\mathrm{M}$, et al. The overexpression of Caveolin-1 and Caveolin-2 correlates with a poor prognosis and tumor progression in esophageal squamous cell carcinoma. Oncol Rep 2007; 18(3): 601-9.

[51] Ho CC, Kuo SH, Huang PH, Huang HY, Yang $\mathrm{CH}$, Yang PC. Caveolin-1 expression is significantly associated with drug resistance and poor prognosis in advanced non-small cell lung cancer patients treated with gemcitabine-based chemotherapy. Lung Cancer 2008; 59(1): 105-10.

[52] Savage K, Lambros MB, Robertson D, et al. Caveolin 1 is overexpressed and amplified in a subset of basal-like and metaplastic breast carcinomas: a morphologic, ultrastructural, immunohistochemical, and in situ hybridization analysis. Clin Cancer Res 2007; 13(1): 90-101.

[53] Parat MO, Anand-Apte B, Fox PL. Differential Caveolin-1 polarization in endothelial cells during migration in two and three dimensions. Mol Biol Cell 2003; 14(8): 3156-68.

[54] Beardsley A, Fang K, Mertz H, Castranova V, Friend S, Liu J. Loss of Caveolin-1 polarity impedes endothelial cell polarization and directional movement. J Biol Chem 2005; 280(5): 3541-7.

[55] Santilman V, Baran J, Anand-Apte B, Evans RM, Parat MO Caveolin-1 polarization in transmigrating endothelial cells requires binding to intermediate filaments. Angiogenesis 2007; 10(4): 297-305.

[56] Ho CC, Huang PH, Huang HY, Chen YH, Yang PC, Hsu SM. Up-regulated Caveolin-1 accentuates the metastasis capability of lung adenocarcinoma by inducing filopodia formation. Am J Pathol 2002; 161(5): 1647-56.

[57] Lee H, Volonte D, Galbiati F, et al. Constitutive and growth factor-regulated phosphorylation of Caveolin- 1 occurs at the same site (Tyr-14) in vivo: identification of a c-Src/Cav1/Grb7 signaling cassette. Mol Endocrinol 2000; 14(11): 1750-75.

[58] Hatanaka M, Maeda T, Ikemoto T, Mori H, Seya T, Shimizu A. Expression of Caveolin-1 in human $\mathrm{T}$ cell leukemia cell lines. Biochem Biophys Res Commun 1998; 253(2): 382-7.

[59] Li L, Yang G, Ebara S, et al. Caveolin-1 mediates testosterone-stimulated survival/clonal growth and promotes metastatic activities in prostate cancer cells. Cancer Res 2001; 61(11): 4386-92.

[60] Garcia S, Dales JP, Charafe-Jauffret E, et al. Poor prognosis in breast carcinomas correlates with increased expression of targetable CD146 and c-Met and with proteomic basal-like phenotype. Hum Pathol 2007; 38(6): 830-41.

[61] Williams TM, Lisanti MP. Caveolin-1 in oncogenic transformation, cancer, and metastasis. Am J Physiol Cell Physiol 2005; 288(3): C494-506.

[62] Felley-Bosco E, Bender FC, Courjault-Gautier F, Bron C, Quest AF. Caveolin-1 down-regulates inducible nitric oxide synthase via the proteasome pathway in human colon carcinoma cells. Proc Natl Acad Sci USA 2000; 97(26): 14334-9.

[63] Felley-Bosco E, Bender F, Quest AF. Caveolin-1-mediated post-transcriptional regulation of inducible nitric oxide synthase in human colon carcinoma cells. Biol Res 2002; 35(2): 169-76. 
[64] Mastick CC, Brady MJ, Saltiel AR. Insulin stimulates the tyrosine phosphorylation of Caveolin. J Cell Biol 1995; 129(6): 1523-31.

[65] Mastick CC, Saltiel AR. Insulin-stimulated tyrosine phosphorylation of Caveolin is specific for the differentiated adipocyte phenotype in 3T3-L1 cells. J Biol Chem 1997; 272(33): 20706-14.

[66] Kimura A, Mora S, Shigematsu S, Pessin JE, Saltiel AR. The insulin receptor catalyzes the tyrosine phosphorylation of Caveolin-1. J Biol Chem 2002; 277(33): 30153-8.

[67] Cao H, Courchesne WE, Mastick CC. A phosphotyrosinedependent protein interaction screen reveals a role for phosphorylation of Caveolin-1 on tyrosine 14: recruitment of C-terminal Src kinase. J Biol Chem 2002; 277(11): 8771-4.

[68] Cao H, Sanguinetti AR, Mastick CC. Oxidative stress activates both Src-kinases and their negative regulator Csk and induces phosphorylation of two targeting proteins for Csk: Caveolin-1 and paxillin. Exp Cell Res 2004; 294(1): 159-71.

[69] Volonte D, Galbiati F, Pestell RG, Lisanti MP. Cellular stress induces the tyrosine phosphorylation of Caveolin-1 (Tyr(14)) via activation of p38 mitogen-activated protein kinase and cSrc kinase. Evidence for caveolae, the actin cytoskeleton, and focal adhesions as mechanical sensors of osmotic stress. J Biol Chem 2001; 276(11): 8094-103.

[70] Labrecque L, Nyalendo C, Langlois S, et al. Src-mediated tyrosine phosphorylation of Caveolin-1 induces its association with membrane type 1 matrix metalloproteinase. J Biol Chem 2004; 279(50): 52132-40.

[71] del Pozo MA, Balasubramanian N, Alderson NB, et al. Phospho-Caveolin-1 mediates integrin-regulated membrane domain internalization. Nat Cell Biol 2005; 7(9): 901-8.

[72] Del Pozo MA, Schwartz MA. Rac, membrane heterogeneity, Caveolin and regulation of growth by integrins. Trends Cell Biol 2007; 17(5): 246-50.

[73] Orlichenko L, Huang B, Krueger E, McNiven MA. Epithelial growth factor-induced phosphorylation of Caveolin 1 at tyrosine 14 stimulates caveolae formation in epithelial cells. $J$ Biol Chem 2006; 281(8): 4570-9.

[74] Fang PK, Solomon KR, Zhuang L, et al. Caveolin-1alpha and -1beta perform nonredundant roles in early vertebrate development. Am J Pathol 2006; 169(6): 2209-22.

[75] Galbiati F, Volonte D, Liu J, et al. Caveolin-1 expression negatively regulates cell cycle progression by inducing $\mathrm{G}(0) / \mathrm{G}(1)$ arrest via a p53/p21(WAF1/Cip1)-dependent mechanism. Mol Biol Cell 2001; 12(8): 2229-44.

[76] Volonte D, Zhang K, Lisanti MP, Galbiati F. Expression of Caveolin-1 induces premature cellular senescence in primary cultures of murine fibroblasts. Mol Biol Cell 2002; 13(7): 2502-17.

[77] Dasari A, Bartholomew JN, Volonte D, Galbiati F. Oxidative stress induces premature senescence by stimulating Caveolin-1 gene transcription through p38 mitogen-activated protein kinase/Sp1-mediated activation of two GC-rich promoter elements. Cancer Res 2006; 66(22): 10805-14.

[78] Galbiati F, Volonte D, Engelman JA, et al. Targeted downregulation of Caveolin-1 is sufficient to drive cell transformation and hyperactivate the p42/44 MAP kinase cascade. EMBO J 1998; 17(22): 6633-48.

[79] Volonte D, Galbiati F, Lisanti MP. Visualization of Caveolin-1, a caveolar marker protein, in living cells using green fluorescent protein (GFP) chimeras. The subcellular distribution of Caveolin-1 is modulated by cell-cell contact. FEBS Lett 1999; 445(2-3): 431-9.

[80] Lu Z, Ghosh S, Wang Z, Hunter T. Downregulation of Caveolin-1 function by EGF leads to the loss of E-cadherin, increased transcriptional activity of beta-catenin, and enhanced tumor cell invasion. Cancer Cell 2003; 4(6): 499515.

[81] Torres VA, Tapia JC, Rodriguez DA, et al. Caveolin-1 controls cell proliferation and cell death by suppressing expression of the inhibitor of apoptosis protein survivin. J Cell Sci 2006; 119(Pt 9): 1812-23.

[82] Rodriguez DA, Tapia JC, Fernandez JG, et al. Caveolin-1mediated suppression of cyclooxygenase-2 via a beta-
catenin-Tcf/Lef-dependent transcriptional mechanism reduced prostaglandin E2 production and survivin expression. Mol Biol Cell 2009; 20(8): 2297-310.

[83] Hulit J, Bash $T$, Fu M, et al. The cyclin D1 gene is transcriptionally repressed by Caveolin-1. J Biol Chem 2000; 275(28): 21203-9.

[84] Wang F, Bhat K, Doucette M, et al. Docosahexaenoic acid (DHA) sensitizes brain tumor cells to etoposide-induced apoptosis. Curr Mol Med 2011; 11(6): 503-11.

[85] Li J, Hassan GS, Williams TM, et al. Loss of Caveolin-1 causes the hyper-proliferation of intestinal crypt stem cells, with increased sensitivity to whole body gamma-radiation. Cell Cycle 2005; 4(12): 1817-25.

[86] Sotgia F, Williams TM, Cohen AW, Minetti C, Pestell RG, Lisanti MP. Caveolin-1-deficient mice have an increased mammary stem cell population with upregulation of Wnt/betacatenin signaling. Cell Cycle 2005; 4(12): 1808-16.

[87] Hnasko R, Lisanti MP. The biology of caveolae: lessons from Caveolin knockout mice and implications for human disease. Mol Interv 2003; 3(8): 445-64.

[88] Le Lay S, Kurzchalia TV. Getting rid of Caveolins: phenotypes of Caveolin-deficient animals. Biochim Biophys Acta 2005; 1746(3): 322-33.

[89] Zhang H, Su L, Muller S, et al. Restoration of Caveolin-1 expression suppresses growth and metastasis of head and neck squamous cell carcinoma. Br J Cancer 2008; 99(10): 1684-94.

[90] Gu D, Li H, Wang Z, Chen Q, Jiang J, Zhu H. Caveolin-1 inhibits the growth of human laryngeal squamous cell carcinoma and down regulates EGFR-MAPKs signaling pathway. Laryngoscope 2007; 117(10): 1782-9.

[91] Gosens R, Stelmack GL, Dueck G, et al. Role of Caveolin-1 in p42/p44 MAP kinase activation and proliferation of human airway smooth muscle. Am J Physiol Lung Cell Mol Physio 2006; 291(3): L523-34.

[92] Vanhaesebroeck B, Alessi DR. The PI3K-PDK1 connection: more than just a road to PKB. Biochem J 2000; 346(Pt 3): 561-76.

[93] Liang J, Slingerland JM. Multiple roles of the PI3K/PKB (Akt) pathway in cell cycle progression. Cell Cycle 2003; 2(4): 33945.

[94] Cully M, You H, Levine AJ, Mak TW. Beyond PTEN mutations: the PI3K pathway as an integrator of multiple inputs during tumorigenesis. Nat Rev Cancer 2006; 6(3): 184-92.

[95] Vanhaesebroeck B, Vogt PK, Rommel C. PI3K: from the bench to the clinic and back. Curr Top Microbiol Immunol 2010; 347: 1-19.

[96] Yu W, Cassara J, Weller PF. Phosphatidylinositide 3-kinase localizes to cytoplasmic lipid bodies in human polymorphonuclear leukocytes and other myeloid-derived cells. Blood 2000; 95(3): 1078-85.

[97] Feng S, Wang $Y$, Wang $X$, et al. Caveolin-1 gene silencing promotes the activation of PI3K/AKT dependent on Eralpha36 and the transformation of MCF10ACE. Sci China Life Sci 2010; 53(5): 598-605.

[98] Xia H, Khalil W, Kahm J, Jessurun J, Kleidon J, Henke CA. Pathologic Caveolin-1 regulation of PTEN in idiopathic pulmonary fibrosis. Am J Pathol 2010; 176(6): 2626-37.

[99] Ono K, Iwanaga $Y$, Hirayama M, Kawamura T, Sowa N, Hasegawa K. Contribution of Caveolin-1 alpha and Akt to TNF-alpha-induced cell death. Am J Physiol Lung Cell Mol Physiol 2004; 287(1): L201-9.

[100] Shack S, Wang XT, Kokkonen GC, Gorospe M, Longo DL, Holbrook NJ. Caveolin-induced activation of the phosphatidylinositol 3-kinase/Akt pathway increases arsenite cytotoxicity. Mol Cell Biol 2003; 23(7): 2407-14.

[101] Zundel W, Swiersz LM, Giaccia A. Caveolin 1-mediated regulation of receptor tyrosine kinase-associated phosphatidylinositol 3-kinase activity by ceramide. Mol Cell Biol 2000; 20(5): 1507-14.

[102] Torres VA, Tapia JC, Rodriguez DA, et al. E-cadherin is required for Caveolin-1-mediated down-regulation of the inhibitor of apoptosis protein survivin via reduced beta- 
catenin-Tcf/Lef-dependent transcription. Mol Cell Biol 2007; 27(21): 7703-17.

[103] Shan T, Ma Q, Guo K, et al. Xanthones from mangosteen extracts as natural chemopreventive agents: potential anticancer drugs. Curr Mol Med 2011; 11(8): 666-77.

[104] Hellwig CT, Passante E, Rehm M. The molecular machinery regulating apoptosis signal transduction and its implication in human physiology and pathophysiologies. Curr Mol Med 2011; 11(1): 31-47.

[105] Zhang W, Yokota H, Xu Z, et al. Hyperoxia Therapy of Preproliferative Ischemic Retinopathy in a Mouse Model. Invest Ophthalmol Vis Sci 2011; 52(9): 6384-95.

[106] Ryter SW, Lee SJ, Choi AM. Autophagy in cigarette smokeinduced chronic obstructive pulmonary disease. Expert Rev Respir Med 2010; 4(5): 573-84.

[107] Ryter SW, Lam HC, Chen ZH, Choi AM. Deadly triplex: smoke, autophagy and apoptosis. Autophagy 2011; 7(4): 436-7.

[108] Zhang XJ, Yang L, Zhao Q, et al. Induction of acetylcholinesterase expression during apoptosis in various cell types. Cell Death Differ 2002; 9(8): 790-800.

[109] Jin QH, He HY, Shi YF, Lu H, Zhang XJ. Overexpression of acetylcholinesterase inhibited cell proliferation and promoted apoptosis in NRK cells. Acta Pharmacol Sin 2004; 25(8): 1013-21.

[110] Park SE, Jeong SH, Yee SB, et al. Interactions of acetylcholinesterase with Caveolin-1 and subsequently with cytochrome $\mathrm{c}$ are required for apoptosome formation. Carcinogenesis 2008; 29(4): 729-37.

[111] Henriquez M, Armisen R, Stutzin A, Quest AF. Cell death by necrosis, a regulated way to go. Curr Mol Med 2008; 8(3): 187-206.

[112] Gargalovic P, Dory L. Cellular apoptosis is associated with increased Caveolin-1 expression in macrophages. J Lipid Res 2003; 44(9): 1622-32.

[113] Yamamoto M, Toya Y, Schwencke C, Lisanti MP, Myers MG, Jr., Ishikawa Y. Caveolin is an activator of insulin receptor signaling. J Biol Chem 1998; 273(41): 26962-8.

[114] Galbiati F, Razani B, Lisanti MP. Emerging themes in lipid rafts and caveolae. Cell 2001; 106(4): 403-11.

[115] Salani B, Briatore L, Garibaldi S, Cordera R, Maggi D. Caveolin-1 down-regulation inhibits insulin-like growth factorI receptor signal transduction in $\mathrm{H} 9 \mathrm{C} 2$ rat cardiomyoblasts. Endocrinology 2008; 149(2): 461-5.

[116] Repetto S, Salani B, Maggi D, Cordera R. Insulin and IGF-I phosphorylate eNOS in HUVECs by a Caveolin-1 dependent mechanism. Biochem Biophys Res Commun 2005; 337(3): 849-52.

[117] Li L, Ren CH, Tahir SA, Ren C, Thompson TC. Caveolin-1 maintains activated Akt in prostate cancer cells through scaffolding domain binding site interactions with and inhibition of serine/threonine protein phosphatases PP1 and PP2A. Mol Cell Biol 2003; 23(24): 9389-404.

[118] Timme TL, Goltsov A, Tahir S, et al. Caveolin-1 is regulated by c-myc and suppresses c-myc-induced apoptosis. Oncogene 2000; 19(29): 3256-65.

[119] Williams TM, Hassan GS, Li J, et al. Caveolin-1 promotes tumor progression in an autochthonous mouse model of prostate cancer: genetic ablation of Cav-1 delays advanced prostate tumor development in tramp mice. $J$ Biol Chem 2005; 280(26): 25134-45.

[120] Zhang X, Ling MT, Wang Q, et al. Identification of a novel inhibitor of differentiation-1 (ID-1) binding partner, Caveolin1 , and its role in epithelial-mesenchymal transition and resistance to apoptosis in prostate cancer cells. J Biol Chem 2007; 282(46): 33284-94.

[121] Head BP, Patel HH, Tsutsumi YM, et al. Caveolin-1 expression is essential for $\mathrm{N}$-methyl-D-aspartate receptormediated Src and extracellular signal-regulated kinase 1/2 activation and protection of primary neurons from ischemic cell death. FASEB J 2008; 22(3): 828-40.

[122] Barzan D, Maier P, Zeller WJ, Wenz F, Herskind C. Overexpression of Caveolin-1 in lymphoblastoid TK6 cells enhances proliferation after irradiation with clinically relevant doses. Strahlenther Onkol 2010; 186(2): 99-106.
[123] Cordes N, Frick S, Brunner TB, et al. Human pancreatic tumor cells are sensitized to ionizing radiation by knockdown of Caveolin-1. Oncogene 2007; 26(48): 6851-62.

[124] Chanvorachote $P$, Nimmannit U, Lu Y, Talbott S, Jiang BH, Rojanasakul Y. Nitric oxide regulates lung carcinoma cell anoikis through inhibition of ubiquitin-proteasomal degradation of Caveolin-1. J Biol Chem 2009; 284(41): 28476-84.

[125] Tang Y, Zeng X, He F, Liao Y, Qian N, Toi M. Caveolin-1 is related to invasion, survival, and poor prognosis in hepatocellular cancer. Med Oncol 2012; 29(2): 977-84.

[126] Zhang Z, Yao K, Jin C. Apoptosis of lens epithelial cells induced by high concentration of glucose is associated with a decrease in Caveolin-1 levels. Mol Vis 2009; 15: 2008-17.

[127] Shen J, Lee W, Li Y, et al. Interaction of Caveolin-1, nitric oxide, and nitric oxide synthases in hypoxic human SK-N-MC neuroblastoma cells. J Neurochem 2008; 107(2): 478-87.

[128] Senou M, Costa MJ, Massart C, et al. Role of Caveolin-1 in thyroid phenotype, cell homeostasis, and hormone synthesis: in vivo study of Caveolin-1 knockout mice. Am J Physiol Endocrinol Metab 2009; 297(2): E438-51.

[129] Jasmin JF, Malhotra S, Singh Dhallu M, Mercier I, Rosenbaum DM, Lisanti MP. Caveolin-1 deficiency increases cerebral ischemic injury. Circ Res 2007; 100(5): 721-9.

[130] Wu CP, Calcagno AM, Ambudkar SV. Reversal of ABC drug transporter-mediated multidrug resistance in cancer cells: evaluation of current strategies. Curr Mol Pharmacol 2008; 1(2): 93-105.

[131] Moon KC, Lee GK, Yoo SH, et al. Expression of Caveolin-1 in pleomorphic carcinoma of the lung is correlated with a poor prognosis. Anticancer Res 2005; 25(6C): 4631-7.

[132] Suzuoki M, Miyamoto M, Kato K, et al. Impact of Caveolin-1 expression on prognosis of pancreatic ductal adenocarcinoma. Br J Cancer 2002; 87(10): 1140-4.

[133] Campbell L, Gumbleton M, Griffiths DF. Caveolin-1 overexpression predicts poor disease-free survival of patients with clinically confined renal cell carcinoma. $\mathrm{Br} \mathrm{J}$ Cancer 2003; 89(10): 1909-13.

[134] Selga E, Morales C, Noe V, Peinado MA, Ciudad CJ. Role of Caveolin 1, E-cadherin, Enolase 2 and PKCalpha on resistance to methotrexate in human HT29 colon cancer cells. BMC Med Genomics 2008; 1: 35.

[135] Belanger MM, Gaudreau M, Roussel E, Couet J. Role of Caveolin-1 in etoposide resistance development in A549 lung cancer cells. Cancer Biol Ther 2004; 3(10): 954-9.

[136] Linge A, Morishima N, Kasper M, Barth K. Bleomycin induces Caveolin-1 and -2 expression in epithelial lung cancer A549 cells. Anticancer Res 2007; 27(3A): 1343-51.

[137] Tirado OM, MacCarthy CM, Fatima N, Villar J, Mateo-Lozano $\mathrm{S}$, Notario V. Caveolin-1 promotes resistance to chemotherapy-induced apoptosis in Ewing's sarcoma cells by modulating PKCalpha phosphorylation. Int J Cancer 2010; 126(2): 426-36.

[138] Thompson TC, Timme TL, Li L, Goltsov A. Caveolin-1, a metastasis-related gene that promotes cell survival in prostate cancer. Apoptosis 1999; 4(4): 233-7.

[139] Nasu Y, Timme TL, Yang G, et al. Suppression of Caveolin expression induces androgen sensitivity in metastatic androgen-insensitive mouse prostate cancer cells. Nat Med 1998; 4(9): 1062-4

[140] Katsogiannou M, El Boustany C, Gackiere F, et al. Caveolae contribute to the apoptosis resistance induced by the alpha(1A)-adrenoceptor in androgen-independent prostate cancer cells. PLoS One 2009; 4(9): e7068.

[141] Park J, Bae E, Lee C, et al. RNA interference-directed Caveolin-1 knockdown sensitizes SN12CPM6 cells to doxorubicin-induced apoptosis and reduces lung metastasis. Tumour Biol 2010; 31(6): 643-50.

[142] Herzog M, Storch CH, Gut P, et al. Knockdown of Caveolin-1 decreases activity of breast cancer resistance protein (BCRP/ABCG2) and increases chemotherapeutic sensitivity. Naunyn Schmiedebergs Arch Pharmacol 2010; 383(1): 1-11.

[143] Demeule M, Jodoin J, Gingras D, Beliveau R. P-glycoprotein is localized in caveolae in resistant cells and in brain capillaries. FEBS Lett 2000; 466(2-3): 219-24. 
[144] Barakat S, Demeule M, Pilorget A, et al. Modulation of pglycoprotein function by Caveolin-1 phosphorylation. J Neurochem 2007; 101(1): 1-8.

[145] Cai C, Chen J. Overexpression of Caveolin-1 induces alteration of multidrug resistance in Hs578T breast adenocarcinoma cells. Int J Cancer 2004; 111(4): 522-9.

[146] Pang A, Au WY, Kwong YL. Caveolin-1 gene is coordinately regulated with the multidrug resistance 1 gene in normal and leukemic bone marrow. Leuk Res 2004; 28(9): 973-7.

[147] Belanger MM, Roussel E, Couet J. Caveolin-1 is downregulated in human lung carcinoma and acts as a candidate tumor suppressor gene. Chest 2004; 125(5 Suppl): 106S.
[148] Storch CH, Ehehalt R, Haefeli WE, Weiss J. Localization of the human breast cancer resistance protein (BCRP/ABCG2) in lipid rafts/caveolae and modulation of its activity by cholesterol in vitro. J Pharmacol Exp Ther 2007; 323(1): 25764.

[149] Liu J, Lee P, Galbiati F, Kitsis RN, Lisanti MP. Caveolin-1 expression sensitizes fibroblastic and epithelial cells to apoptotic stimulation. Am J Physiol Cell Physiol 2001 280(4): C823-35.

[150] Zhang M, Lin L, Lee SJ, et al. Deletion of Caveolin-1 protects hyperoxia-induced apoptosis via survivin-mediated pathways. Am J Physiol Lung Cell Mol Physiol 2009; 297(5): L945-53. 